\title{
Espécies de plantas de cobertura no recondicionamento químico e físico do solo
}

\author{
Dione P. Cardoso¹, Marx L. N. Silva², Gabriel J. de Carvalho³, Diego A. F. de Freitas ${ }^{4}$ \& Junior C. Avanzi ${ }^{5}$

\begin{abstract}
1 Universidade Federal do Tocantins, Campus de Gurupi, Rua Badejós, Lote 7, Chácaras 69/72, Zona Rural, CEP 77402-970, Gurupi-TO, Brasil, E-mail: cardoso.dione@gmail.com ${ }^{2}$ Universidade Federal de Lavras, Departamento de Ciência do Solo, Centro, CEP 37200-000, Lavras-MG, Brasil. Caixa Postal 3037. E-mail: marx@dcs.ufla.br

${ }^{3}$ Universidade Federal de Lavras, Departamento de Agricultura, Centro, CEP 37200-000, Lavras-MG, Brasil. Caixa Postal 3037. E-mail: gab@dag.ufla.br

${ }^{4}$ Universidade Federal de São João Del-Rei, Câmpus de Sete Lagoas, Centro, CEP 35701-970, Sete Lagoas-MG, Brasil. Caixa Postal 47. E-mail: diego_ufla@yahoo.com.br

${ }^{5}$ Embrapa Pesca e Aquicultura, Quadra 103 Sul - I, Av. JK,164, Centro, CEP 77015-012, Palmas-TO, Brasil. E-mail: junior.avanzi@embrapa.br
\end{abstract}

\section{RESUMO}

O cultivo das plantas de cobertura pode proporcionar melhorias e reestruturação de atributos químicos e físicos do solo, reduzir a resistência do solo à penetração e aumentar a permeabilidade do solo à água reduzindo, assim, a erosão hídrica, razão pela qual se objetivou com este trabalho, avaliar o potencial de espécies de plantas de cobertura no recondicionamento dos atributos químicos e físicos do solo. O experimento foi instalado no município de Lavras, região Sul do Estado de Minas Gerais, sendo as espécies de plantas de cobertura cultivadas sobre um Argissolo Vermelho Amarelo distrófico. Os tratamentos instalados foram: Crotalaria juncea L. (crotalária), Canavalia ensiformis DC. (feijão-de-porco) e Pennisetum sp Rich (milheto), cultivadas nos espaçamentos de 0,25 e 0,50 m entre linhas. Os atributos químicos e físicos analisados foram: pH em água, macronutrientes, matéria orgânica do solo, densidade do solo, volume total de poros, microporosidade, macroporosidade, condutividade hidráulica do solo saturado, umidade e temperatura do solo, estabilidade de agregados e resistência do solo à penetração. As plantas de cobertura influenciaram a disponibilidade de potássio e fósforo porém os demais atributos químicos não foram modificados. A densidade do solo, volume total de poros, micro e macroporosidade não foram alterados após o cultivo das plantas de cobertura, independente dos espaçamentos utilizados. As plantas de cobertura reduziram a resistência do solo à penetração para valores não restritivos ao crescimento das raízes, até a profundidade de $0,25 \mathrm{~m}$.

Palavras-chave: Argissolo Vermelho Amarelo, Fabaceae, Poaceae

\section{Potential of cover plant species in reconditioning of physical and chemical properties of soil}

\begin{abstract}
Soil cover crops may provide improvement and restructuring of chemical and physical soil properties, reduce the soil resistance to penetration and increase soil permeability, thus reducing water erosion. Therefore, this work aimed to evaluate the potential of cover crops in the reconditioning the chemical and physical properties of soil. The experiment was conducted in Lavras in the region south of Minas Gerais State, and the cover crops were planted on a distrophic Hapludult. The treatments consisted of Crotalaria juncea L. (sunn hemp), Canavalia ensiformis DC. (jack-bean) and Pennisetum sp Rich (pearl millet), grown in between-rows with spacings of 0.25 and $0.50 \mathrm{~m}$. The chemical and physical properties analysed were $\mathrm{pH}$, macronutrients, soil organic matter, bulk density, total porosity, microporosity, macroporosity, saturated hydraulic conductivity, soil temperature and moisture, aggregate stability and soil penetration resistance. There was influence of cover crops on the potassium and phosphorus availability in soil, but other chemical properties were not modified. The bulk density, total porosity, micro and macroporosity were not changed after cultivation of cover crops, regardless of row length used. The cover crops reduced the soil penetration resistance values for nonrestrictive to root growth to $0.25 \mathrm{~m}$ depth.
\end{abstract}

Key words: Hapludult, Fabaceae, Poaceae 


\section{Introdução}

O desenvolvimento sustentável tem, por objetivo, a produção combinada com conservação dos recursos naturais, como a água e o solo, mediante adoção de práticas conservacionistas dentre as quais se destaca o cultivo de espécies de plantas de cobertura que protegem o solo da redução da perda d'água por evaporação e também do impacto direto das gotas da chuva reduzindo o escoamento superficial $\mathrm{e}$, consequentemente, o processo erosivo. Outro aspecto conservacionista relacionado ao uso de plantas de cobertura é o provável melhoramento e reestruturação dos atributos químicos e físicos do solo. Assim, o uso de espécies que tenham sistema radicular vigoroso, com capacidade de crescer em solos com alta resistência à penetração, criando poros por onde as raízes da cultura subsequente possam crescer, tem sido utilizado como alternativa à escarificação mecânica, para reduzir a compactação do solo (Stone \& Silveira, 2001; Silva \& Rosolem, 2002).

Dentre as espécies de plantas de cobertura com potencial para reestruturação dos atributos químicos e físicos do solo, adaptadas às condições climáticas e aos solos da região Sul de Minas Gerais, se destacam as espécies Crotalaria juncea L. e Canavalia ensiformis DC. (Fabaceae) e Pennisetum sp Rich (Poaceae), as quais são comumente conhecidas como crotalária, feijão-de-porco e milheto, respectivamente. Essas plantas são as mesmas sugeridas como adubos verdes por Bertoni \& Lombardi Neto (2005).

A crotalária tem crescimento inicial rápido e o feijão-deporco crescimento inicial lento; ambas têm raízes vigorosas, profundas e ramificadas que favorecem a ciclagem dos nutrientes disponívies nas camadas subsuperficiais; na crotalária a absorção de nutrientes ocorre das camadas subsuperficiais até a superfície, desde que não exista camada de impedimento do solo (Burle et al., 2006). Esses nutrientes constituirão a fitomassa e serão liberados durante a decomposição, favorecendo o acúmulo nas camadas superficiais do solo.

$\mathrm{O}$ milheto tem crescimento vegetativo inicial rápido, raízes fasciculadas, profundas e abundantes mas não fixam o nitrogênio atmosférico; deste modo, são consideradas somente como plantas protetoras do solo (Burle et al., 2006).

Conforme Calegari et al. (1993) os possíveis efeitos dessas plantas de cobertura nos atributos químicos do solo são: aumento do teor de matéria orgânica, da disponibilidade de micro e macronutrientes, da CTC efetiva e do $\mathrm{pH}$; diminuição dos teores de alumínio trocável e da acidez; incremento da capacidade de reciclagem e mobilização de nutrientes lixiviados ou pouco solúveis presentes nas camadas subsuperficiais do solo. Os prováveis efeitos sobre os atributos físicos do solo são: redução da resistência do solo à penetração, da evaporação de água do solo, da oscilação da temperatura e da perda de umidade do solo e melhoria da taxa de infiltração, o que reflete em redução das perdas de solo, água, nutrientes e carbono orgânico.

Anghinoni \& Nicolodi (2004) afirmam que os efeitos proporcionados pelos compostos orgânicos dos resíduos vegetais de plantas de cobertura sobre a química do solo, são transientes, mas podem mitigar os efeitos acidificantes causados por grupos carboxílicos e fenólicos, gerados durante a decomposição de resíduos vegetais, e pela exportação de minerais como $\mathrm{Ca}, \mathrm{Mg}$ e $\mathrm{K}$, pelas colheitas. De acordo com Nuernberg et al. (1986), as plantas que produzem raízes profundas, com crescimento inicial rápido e agressivo, podem recuperar solos fisicamente degradados, visto que reduzem a resistência do solo à penetração das raízes. Para Allmaras et al. (1965), o diâmetro médio geométrico é influenciado pelo tipo de equipamento, tipo de preparo do solo e espécies de plantas utilizadas; desta forma, o uso de plantas de cobertura pode ser uma alternativa para melhorar os atributos físicos do solo.

Pelo exposto, objetivou-se avaliar neste trabalho, o potencial de recondicionamento dos atributos químicos e físicos de um Argissolo Vermelho Amarelo, por meio do manejo da crotalária, feijão-de-porco e milheto, nos espaçamentos de 0,25 e 0,50 m entre linhas, no Sul de Minas Gerais.

\section{Material e Métodos}

O experimento foi instalado no câmpus da Universidade Federal de Lavras localizado no município de Lavras, região Sul de Minas Gerias, entre as coordenadas geográficas $21^{\circ} 13^{\prime} 20^{\prime \prime}$ de latitude sul e $44^{\circ} 58^{\prime} 17^{\prime \prime}$ de longitude oeste. As espécies de plantas de cobertura foram semeadas em um Argissolo Vermelho Amarelo distrófico (Embrapa, 2006), com textura do horizonte superficial e subsuperficial argilosa e relevo suave-ondulado (declive de 6\%). O clima da região é classificado como Cwa, conforme Köppen e se caracteriza como clima subtropical de inverno seco e verão quente (Brasil, 1992). A Figura 1 mostra os valores médios de precipitação e temperatura a cada 15 dias após a semeadura (DAS) das espécies de plantas de cobertura.

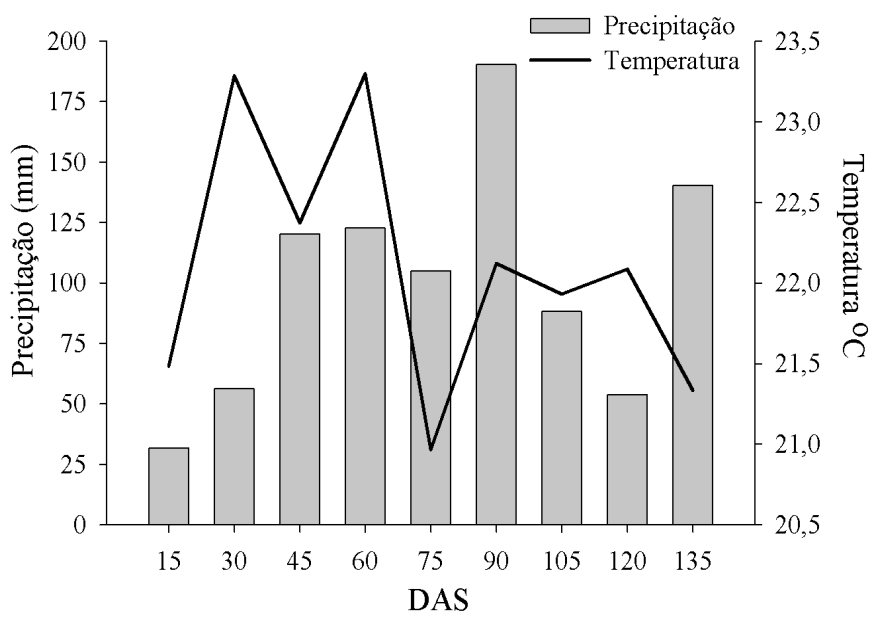

Figura 1. Precipitação pluvial e temperatura média a cada 15 dias após a semeadura das plantas de cobertura, obtidas na Estação Climatológica Principal de Lavras

Os tratamentos foram constituídos pela crotalária, feijão-de-porco e milheto, cultivadas nos espaçamentos de 0,25 e $0,50 \mathrm{~m}$ entre linhas, instalados em seis parcelas com tamanho de 4 × $12 \mathrm{~m}$, sendo a maior dimensão no sentido do declive do terreno. $\mathrm{O}$ delineamento experimental utilizado foi o delineamento inteiramente casualizados, com três repetições. 
Dentre os atributos químicos analisados: o $\mathrm{pH}$ em água, os macronutrientes ( $\mathrm{P}, \mathrm{P}-\mathrm{rem}, \mathrm{K}^{+}, \mathrm{Ca}^{2+} \mathrm{e} \mathrm{Mg}^{2+}$ ), os parâmetros de fertilidade química $\left(\mathrm{Al}^{3+}, \mathrm{H}+\mathrm{Al}, \mathrm{SB}, \mathrm{t}, \mathrm{T}, \mathrm{V}\right.$ e m) e a matéria orgânica foram determinados conforme Embrapa (1997). Os atributos físicos do solo analisados foram: densidade do solo (Blake \& Hartge, 1986), volume total de poros (Danielson \& Sutherland, 1986), micro e macroporosidade (Grohmann, 1960), umidade e temperatura do solo na profundidade de $5 \mathrm{~cm}$, estabilidade de agregados via úmida, expressos pelo diâmetro médio geométrico (DMG) e diâmetro médio ponderado (DMP) (Embrapa, 1997), condutividade hidráulica do solo saturado (Ksat) (Embrapa, 1997) e resistência do solo à penetração (Stolf, 1991). Não houve correção da fertilidade química nem preparo do solo com revolvimento para a semeadura.

As coletas de solo para análises dos atributos físicos e químicos foram realizadas antes da semeadura (testemunha) e 27 dias após o corte das plantas de cobertura (130 dias após a semeadura), o que corresponde ao início da decomposição da fitomassa, nas profundidades de $0-20 \mathrm{~cm}$.

Os dados obtidos foram submetidos à análise de variância sendo utilizados o programa Sisvar (Ferreira, 2000) e o teste, de acordo com Scott \& Knott (1974), a nível de significância de $5 \%$, para comparar os tratamentos.

\section{Resultados e Discussão}

$\mathrm{Na}$ Tabela 1 observa-se que o $\mathrm{pH}$ do solo não variou ao longo do cultivo das plantas de cobertura e do início da decomposição dos resíduos vegetais, sendo que o solo manteve seu teor de acidez médio (Ribeiro et al., 1999). Almeida et al. (2008) não verificaram, após três anos manejado com plantio direto, efeito significativo da crotalária e do milheto sobre o $\mathrm{pH}$ do solo.

Os teores de $\mathrm{Ca}, \mathrm{Mg}, \mathrm{Al}$, acidez potencial $(\mathrm{H}+\mathrm{Al})$, soma de bases, capacidade de troca catiônica $(\mathrm{t})$ e capacidade de troca catiônica a pH 7,0 (T) não sinalizaram diferenças entre as espécies de plantas de cobertura utilizadas e a testemunha (Tabela 1), porém resultados diferentes foram encontrados por Faria et al. (2004), ao verificarem que a crotalária e o feijão-deporco, ceifados e deixados na superfície do terreno, melhoraram os atributos químicos do solo aumentando o Ca trocável, o valor da capacidade de troca catiônica (CTC) e o teor da matéria orgânica (MO) até a profundidade de $10 \mathrm{~cm}$. Conforme esses mesmos autores, na camada de $10-20 \mathrm{~cm}$ houve redução no teor de Ca trocável e na capacidade de troca catiônica (CTC), para as primeira e nona safras, respectivamente.

O Argissolo Vermelho Amarelo estudado tem acidez média, com teores de Al trocável de $0,1 \mathrm{e} 0,2 \mathrm{cmol}_{\mathrm{c}} \mathrm{dm}^{-3}$ (Tabela 1 ). Esses baixos valores de $\mathrm{Al}$ trocável ocorreram uma vez que o pH se encontrava com valor próximo a 5,5 e neste $\mathrm{pH}$ o Al trocável é precipitado e também pode ocorrer a formação de complexos com ácidos orgânicos fazendo com que a atividade do alumínio na solução seja reduzida (Delhaize \& Ryan, 1995; Schlindwein et al., 2003).

$\mathrm{O}$ teor de $\mathrm{P}$ no solo aumentou $0,6 \mathrm{mg} \mathrm{dm}^{-3}$ quando este foi cultivado com feijão-de-porco e milheto, no espaçamento de $0,25 \mathrm{~m}$. Este incremento de $\mathrm{P}$ pode estar relacionado à capacidade dessas plantas em absorverem o $\mathrm{P}$ de camadas subsuperficiais do solo e disponibilizá-lo na superfície, após a decomposição da palha. Torres et al. (2008) verificaram que o milheto foi a espécie de planta de cobertura que mais acumulou $\mathrm{P}$, porém esses autores não avaliaram a acumulação deste nutriente pelo feijão-de-porco. Menezes \& Leandro (2004) observaram, comparando oito espécies de plantas de cobertura, que o milheto e a braquiária acumularam maiores quantidades de P. Silveira et al. (2010) constataram que a cultura do milheto diferiu do tratamento controle somente nos teores de P nas camadas de 5-10 e 10-20 cm.

$\mathrm{O}$ teor de $\mathrm{K}$ variou de 47 a $76 \mathrm{mg} \mathrm{dm}^{-3}$, sendo o maior valor encontrado na testemunha e no feijão-de-porco, no espaçamento de $0,25 \mathrm{~m}$; os demais tratamentos mostraram redução no teor de $\mathrm{K}$ no solo, com destaque para a crotalária, que teve o menor teor deste elemento, com valores de 47 e 51 $\mathrm{mg} \mathrm{dm}{ }^{-3}$ nos espaçamentos de 0,25 e $0,50 \mathrm{~m}$, respectivamente. Esta redução é consequência da exigência nutricional da cultura e também da imobilização do nutriente na fitomassa.

O cultivo das plantas de cobertura, independente dos espaçamentos utilizados, não modificou o teor de matéria orgânica do solo. Almeida et al. (2008) mesmo avaliando um Latossolo Vermelho distroférrico (LVdf) típico argiloso manejado por três anos com sistema plantio direto, também não verificaram efeito da crotalária e do milheto no teor de matéria orgânica do solo.

Silveira et al. (2010) não verificaram diferenças nos atributos químicos do solo, em diferentes camadas, quando

Tabela 1. Atributos químicos do Argissolo Vermelho-Amarelo antes do cultivo (testemunha) e 27 dias após o corte da fitomassa

\begin{tabular}{|c|c|c|c|c|c|c|c|}
\hline \multirow{2}{*}{ Atributos } & \multirow{2}{*}{ Testemunha } & \multicolumn{6}{|c|}{ Após o corte } \\
\hline & & $\mathrm{C}_{0,25}$ & $\mathrm{C}_{\mathbf{0 , 5 0}}$ & $\mathbf{F}_{0,25}$ & $\mathbf{F}_{\mathbf{0 , 5 0}}$ & $\mathbf{M}_{0,25}$ & $\mathbf{M}_{0,50}$ \\
\hline $\mathrm{pH}\left(\mathrm{H}_{2} \mathrm{O}\right)$ & $5,4 a$ & $5,4 a$ & $5,5 a$ & $5,3 a$ & $5,2 a$ & $5,5 a$ & $5,6 a$ \\
\hline$P\left(\mathrm{mg} \mathrm{dm}^{-3}\right)$ & $2,8 b$ & $2,8 b$ & $3,1 b$ & $3,4 a$ & $2,8 b$ & $3,4 a$ & $2,8 b$ \\
\hline $\mathrm{K}\left(\mathrm{mg} \mathrm{dm} \mathrm{m}^{-3}\right)$ & $76 \mathrm{a}$ & $47 c$ & $51 c$ & $70 a$ & $56 b$ & $59 b$ & $59 b$ \\
\hline $\mathrm{Ca}^{2+}\left(\mathrm{cmol}_{\mathrm{c}} \mathrm{dm}^{-3}\right)$ & $1,8 a$ & $1,5 \mathrm{a}$ & $1,7 a$ & $1,6 \mathrm{a}$ & $1,5 a$ & $1,6 a$ & $1,7 a$ \\
\hline $\mathrm{Mg}^{2+}\left(\mathrm{cmol}_{\mathrm{c}} \mathrm{dm}^{-3}\right)$ & $0,5 a$ & $0,4 a$ & $0,5 a$ & $0,4 a$ & $0,4 a$ & $0,5 a$ & $0,5 a$ \\
\hline $\mathrm{Al}^{3+}\left(\mathrm{cmol}_{\mathrm{c}} \mathrm{dm}^{-3}\right)$ & $0,1 \mathrm{a}$ & $0,2 a$ & $0,2 a$ & $0,2 a$ & $0,2 a$ & $0,2 a$ & $0,2 a$ \\
\hline $\mathrm{H}+\mathrm{Al}\left(\mathrm{cmol}_{\mathrm{c}} \mathrm{dm}^{-3}\right)$ & $3,2 a$ & $3,6 a$ & $3,6 a$ & $3,2 a$ & $3,6 a$ & $3,6 a$ & $3,6 a$ \\
\hline $\mathrm{SB}\left(\mathrm{cmol}_{\mathrm{c}} \mathrm{dm}^{-3}\right)$ & $2,5 a$ & $2,0 a$ & $2,3 a$ & $2,2 a$ & $2,0 a$ & $2,3 a$ & $2,5 a$ \\
\hline $\mathrm{t}\left(\mathrm{cmol}_{\mathrm{c}} \mathrm{dm}^{-3}\right)$ & $2,5 a$ & $2,2 a$ & $2,5 a$ & $2,4 a$ & $2,2 a$ & $2,5 a$ & $2,7 a$ \\
\hline $\mathrm{T}\left(\mathrm{cmol}_{\mathrm{c}} \mathrm{dm}^{-3}\right)$ & $5,7 a$ & $5,6 a$ & $5,9 a$ & $5,4 a$ & $5,6 a$ & $5,9 a$ & $6,1 a$ \\
\hline $\mathrm{MO}\left(\mathrm{g} \mathrm{kg}^{-1}\right)$ & $24 a$ & $21 a$ & $24 a$ & $22 a$ & $20 a$ & $20 a$ & $21 a$ \\
\hline
\end{tabular}

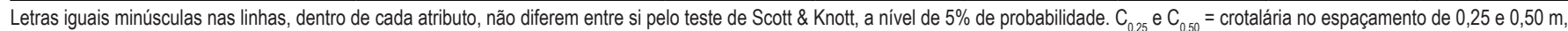
respectivamente; $F_{0,25}$ e $F_{0,50}=$ feijão-de-porco no espaçamento de 0,25 e $0,50 \mathrm{~m}$, respectivamente; $\mathrm{M}_{0,25}$ e $\mathrm{M}_{0,50}=$ milheto no espaçamento de 0,25 e $0,50 \mathrm{~m}$, respectivamente; $\mathrm{P}=$ fósforo; $\mathrm{K}=$ potássio; $\mathrm{Ca}$ = cálcio; $\mathrm{Mg}$ = magnésio; $\mathrm{Al}=$ alumínio; $\mathrm{H}+\mathrm{Al}=$ acidez potencial; $\mathrm{SB}$ = soma de bases trocáveis; $\mathrm{t}$ = capacidade de troca catiônica; $\mathrm{T}$ = capacidade de troca catiônica a pH 7,0; $\mathrm{MO}$ = matéria orgânica; P-rem = fósforo remanescente. 
cultivado com crotalária. Moreti et al. (2007) não observaram, trabalhando com crotalária e milheto, alteração dos atributos químicos do solo após o cultivo do milheto e da crotalária.

Torres \& Pereira (2008) confirmam maior acúmulo de K em gramíneas e maior liberação deste elemento no milheto, aveia, braquiária e crotalária, nos primeiros 42 dias após o manejo.

Observam-se, na Tabela 2, os atributos físicos do Argissolo Vermelho-Amarelo antes e após o estabelecimento das espécies de plantas de cobertura nos espaçamentos entre linhas de 0,25 e $0,50 \mathrm{~m}$. Os valores referentes à densidade do solo (Ds), volume total de poros (VTP), micro e macroporosidade, não mostraram diferenças antes da semeadura e 27 dias após o corte das plantas de cobertura. Resultados semelhantes obtiveram Nascimento et al. (2005) que avaliaram 12 espécies da família Fabaceae, entre elas crotalária e feijão-de-porco, as quais mantiveram inalterados a densidade do solo e o volume total de poros de um Luvissolo, durante o período de três anos. Fabian (2009) embora estudando diversas espécies de plantas de cobertura, não encontrou diferenças nos atributos Ds, VTP, micro e macroporosidade entre as parcelas cultivadas com milheto ou crotalária e a parcela de pousio sendo que, nesses cultivos, referidos atributos diferiram apenas das parcelas com ausência de cobertura vegetal.

Reinert et al. (2008) afirmam que até uma densidade de $1,75 \mathrm{~g} \mathrm{~cm}^{-3}$ o crescimento do sistema radicular das plantas de cobertura seria normal. Como a densidade do solo variou na camada de $0-20 \mathrm{~cm}$, de 1,23 a $1,29 \mathrm{~g} \mathrm{~cm}^{-3}$, pode-se inferir que a densidade do solo não foi fator limitante ao crescimento das plantas. Segundo Camargo \& Alleoni (1997), os macroporos são os caminhos preferenciais para o crescimento das raízes e sua diminuição prejudica o desenvolvimento radicular das plantas; neste estudo, a porosidade total do solo não foi alterada após o cultivo das espécies de plantas de cobertura, o que não comprometeu a capacidade das raízes crescerem na camada de $0-20 \mathrm{~cm}$ do solo.

A Ds, o VTP, a micro e a macroporosidade, são importantes indicadores da qualidade dos solos pois estão relacionados à estrutura e seu estudo complementa a avaliação do arranjo entre sólidos e vazios e, consequentemente, são de grande importância nos processos físicos, químicos e biológicos do solo, como infiltração, condutividade, drenagem, retenção de água, difusão de nutrientes, crescimento de micro-organismos, raízes e pelos absorventes (Bouma, 1991; Moreira \& Siqueira, 2002), porém nesse estudo, o cultivo das espécies de plantas de cobertura durante uma safra, não foi eficiente para modificar esses atributos físicos indicadores da qualidade do solo.

A condutividade hidráulica do solo saturado (Ksat) aumentou após o cultivo da crotalária no espaçamento de 0,25 m (Tabela 3), sinal de que as raízes desta planta de cobertura, cultivada neste espaçamento, podem modificar a condutividade hidráulica do solo, aumentando a infiltração de água. Este efeito se torna importante visto que a erosão hídrica é o principal meio de degradação dos solos brasileiros (Lessa et al., 2007) e o cultivo desta espécie pode aumentar a permeabilidade do solo à água, reduzir o escoamento superficial e, em contrapartida, a erosão dos solos.

O cultivo do feijão-de-porco e milheto no espaçamento de $0,50 \mathrm{~m}$ provocou redução da condutividade hidráulica do solo $\left(7,20\right.$ e $24,0 \mathrm{~mm} \mathrm{~h}^{-1}$, respectivamente) quando comparado às áreas anteriores ao cultivo. $\mathrm{O}$ cultivo dessas plantas no espaçamento de $0,25 \mathrm{~m}$ não alterou a condutividade hidráulica do solo; assim, deve-se cultivar essas plantas de cobertura preferencialmente, no espaçamento de $0,25 \mathrm{~m}$ entre plantas, quando se busca uma infiltração maior de água no solo e, consequentemente, redução da erosão hídrica.

Tabela 2. Densidade do solo (Ds), volume total de poros (VTP), microporosidade (Micro) e macroporosidade (Macro) de um Argissolo Vermelho Amarelo antes e após o corte das plantas de cobertura

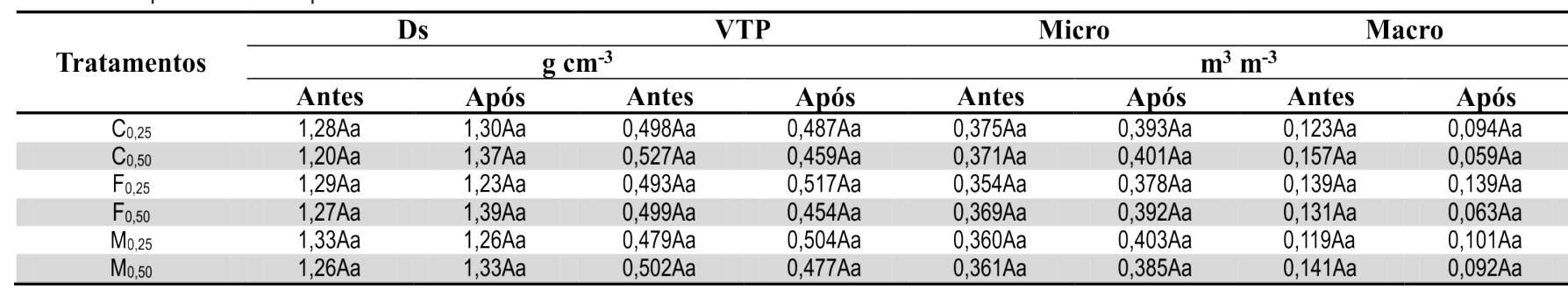

Letras iguais maiúsculas nas linhas e minúsculas nas colunas, dentro de cada atributo, não diferem entre si pelo teste de Scott \& Knott, ao nível de $5 \%$ de probabilidade. Antes = situação anterior ao plantio; Após = situação após o corte das plantas de cobertura; $\mathrm{C}_{0,25}$ e $\mathrm{C}_{0,50}=$ crotalária no espaçamento de 0,25 e $0,50 \mathrm{~m}$, respectivamente; $\mathrm{F}_{0,25}$ e $\mathrm{F}_{0,50}=$ feijão-de-porco no espaçamento de 0,25 e 0,50 $\mathrm{m}$, respectivamente; $\mathrm{M}_{0,25}$ e $\mathrm{M}_{0,50}=$ milheto no espaçamento de 0,25 e $0,50 \mathrm{~m}$, respectivamente.

Tabela 3. Condutividade hidráulica do solo saturado (Ksat), umidade e temperatura de um Argissolo Vermelho-Amarelo antes e após a semeadura das espécies de plantas de cobertura

\begin{tabular}{|c|c|c|c|c|c|c|}
\hline \multirow{3}{*}{ Tratamentos } & \multirow{2}{*}{\multicolumn{2}{|c|}{$\frac{\text { Ksat }}{\mathrm{mm} \mathrm{h}^{-1}}$}} & \multicolumn{2}{|c|}{ Umidade } & \multicolumn{2}{|c|}{ Temperatura } \\
\hline & & & & & \multicolumn{2}{|c|}{${ }^{\circ} \mathrm{C}$} \\
\hline & Antes & Após & Antes & Após & Antes & Após \\
\hline $\mathrm{C}_{0,25}$ & $22,5 \mathrm{Bc}$ & $63,6 \mathrm{Aa}$ & $0,209 \mathrm{Aa}$ & $0,180 \mathrm{Bb}$ & $18,3 \mathrm{Ba}$ & $23,9 \mathrm{Ab}$ \\
\hline $\mathrm{C}_{0,50}$ & $25,9 A c$ & $19,2 \mathrm{Ab}$ & $0,233 \mathrm{Aa}$ & $0,177 \mathrm{Bb}$ & $18,7 \mathrm{Ba}$ & $27,7 \mathrm{Aa}$ \\
\hline $\mathrm{F}_{0,25}$ & $50,9 \mathrm{Ab}$ & $73,2 \mathrm{Aa}$ & $0,213 \mathrm{Aa}$ & $0,203 A b$ & $18,1 \mathrm{Ba}$ & $25,3 \mathrm{Ab}$ \\
\hline $\mathrm{F}_{0,50}$ & $61,8 \mathrm{Ab}$ & $7,2 \mathrm{Bc}$ & $0,232 \mathrm{Aa}$ & $0,198 \mathrm{Ab}$ & $18,7 \mathrm{Ba}$ & $27,9 \mathrm{Aa}$ \\
\hline $\mathrm{M}_{0,25}$ & $43,3 \mathrm{Ab}$ & $32,4 \mathrm{Ab}$ & $0,231 \mathrm{Aa}$ & $0,189 \mathrm{Bb}$ & $19,4 \mathrm{Ba}$ & $23,7 \mathrm{Ab}$ \\
\hline $\mathrm{M}_{0,50}$ & $107,4 \mathrm{Aa}$ & $24,0 \mathrm{Bb}$ & $0,224 \mathrm{Aa}$ & $0,181 \mathrm{Bb}$ & $19,3 \mathrm{Ba}$ & $27,6 \mathrm{Aa}$ \\
\hline
\end{tabular}

Letras iguais maiúsculas nas linhas e minúsculas nas colunas dentro de cada atributo, não diferem entre si pelo teste de Scott \& Knott, a nível de $5 \%$ de probabilidade. Antes = situação anterior ao plantio; Após = situação após o corte das plantas de cobertura; $\mathrm{C}_{0,25}$ e $\mathrm{C}_{0,50}=$ crotalária no espaçamento de 0,25 e 0,50 m, respectivamente; $\mathrm{F}_{0,25}$ e $\mathrm{F}_{0,50}=$ feijão-de-porco no espaçamento de 0,25 e 0,50 $\mathrm{m}$, respectivamente; $\mathrm{M}_{0,25}$ e $\mathrm{M}_{0,50}=$ milheto no espaçamento de 0,25 e $0,50 \mathrm{~m}$, respectivamente. 
A umidade do solo (Us) foi reduzida nas parcelas cultivadas com milheto e crotalária, independente do espaçamento utilizado (Tabela 3) e permaneceu inalterada nas parcelas cultivadas com feijão-de-porco no espaçamento de 0,25 e 0,50 $\mathrm{m}$. As parcelas cultivadas com feijão-de-porco mantiveram a umidade do solo, haja vista que esta cultura tem um elevado índice de cobertura (Cardoso, 2009) que permite manter a umidade e reduzir a incidência direta da radiação solar no solo; as demais espécies de plantas de cobertura utilizadas neste estudo apresentaram índice de cobertura inferior e, por isso, a umidade do solo reduziu. A umidade do solo foi igual entre os tratamentos quando analisada antes da semeadura ou após o corte das plantas de cobertura, sendo que esses valores refletem as épocas de amostragem e quantidade de chuvas precipitadas na região.

A temperatura do solo (Ts) foi menor antes da semeadura das espécies de plantas de cobertura (Tabela 3); este fato ocorreu na época de amostragem, novembro de 2007, quando os valores de temperatura foram menores que na época de corte das plantas de cobertura, visto que a temperatura do solo na camada superficial tende a refletir a temperatura ambiental.

As semeaduras realizados no espaçamento de $0,50 \mathrm{~m}$ entre plantas mostraram temperatura superior àquelas cultivadas no espaçamento de $0,25 \mathrm{~m}$, diferença esta explicada pelo menor índice de cobertura vegetal no espaçamento de $0,50 \mathrm{~m}$, ou seja, a superfície do solo não fica totalmente protegida da radiação solar incidente; em contrapartida, há um aquecimento maior na superfície do solo. Segundo Cardoso (2009), o feijãode-porco e o milheto cultivados no espaçamento de 0,25 $\mathrm{m}$, atingem elevada produção de fitomassa a qual, exposta sobre a superfície do solo, mantém uma temperatura menor pois a radiação solar incidiu com menor intensidade sobre a superfície do solo.

Na Tabela 4 observa-se o efeito das plantas de cobertura sobre a estabilidade dos agregados do solo, representado pelo DMG e DMP. Constata-se que todos os tratamentos cultivados no espaçamento de $0,25 \mathrm{~m}$ sinalizaram aumento no DMG quando comparado com o da testemunha (situação do solo anterior à incorporação das plantas de cobertura). Neste espaçamento, a quantidade de plantas na parcela foi superior e o maior crescimento de raízes no perfil do solo promove aumentos de exsudados orgânicos liberados pelas raízes e da matéria orgânica, que atuará na formação de agregados estáveis pois a agregação do solo é condicionada por substâncias agregantes, ou seja, por substâncias que possuem ação cimentante e aglutinadora (Mielniczuk, 1999).

De acordo com Bavel (1949), o diâmetro médio geométrico dos agregados é um índice sensível ao estado de agregação do solo permitindo, desta maneira, uma avaliação quantitativa da estrutura do solo. Assim, a crotalária, o feijão-de-porco e o milheto favorecem, quando semeados no espaçamento de 0,25 $\mathrm{m}, \mathrm{o}$ aumento da estabilidade dos agregados do solo em água.

A estrutura do solo está relacionada com a agregação e esta tem sido usada como indicador da qualidade física do solo, por ser sensível às alterações, conforme o manejo adotado (Wendling et al., 2005). A crotalária, o feijão-de-porco e o milheto favoreceram, quando semeados no espaçamento de $0,25 \mathrm{~m}$, o aumento da estabilidade dos agregados do solo em água (Tabela 4). Os valores encontrados nesse estudo são superiores aos encontrados por Portugal et al. (2010), Oliveira et al. (2010) e Hickmann et al.(2011), em Argissolos sob diferentes usos. Desta forma, quando as plantas de cobertura são cultivadas no espaçamento de $0,25 \mathrm{~m}$ propiciam maior agregação do solo, o que resulta em também maior resistência à erosão hídrica.

$\mathrm{Na}$ comparação entre a área testemunha e as espécies de plantas de cobertura não foram observadas diferenças no diâmetro médio ponderado (DMP). Tisdall \& Oades (1982) afirmam que elevados valores de massa de raízes e de teores de matéria orgânica resultam em elevados valores de DMP dos agregados porém neste estudo, independente do espaçamento de plantas utilizado, não foi observada alteração do DMP.

$\mathrm{Na}$ Tabela 4 observa-se uma diminuição brusca da percentagem média dos agregados, do maior diâmetro para os demais, em todas as parcelas com plantas de cobertura. Tais resultados demonstram que este solo mostra uma elevada estabilidade dos agregados o que reflete em atributos físicos com valores adequados.

Segundo Carpenedo \& Mielniczuk (1990), há maior estabilidade dos agregados em solos sob gramíneas do que em solos sob leguminosas. Este efeito pode ser atribuindo à ação mecânica das raízes das gramíneas, associada ao grande número de raízes por volume de solo e ao seu diâmetro reduzido (D’Agostini, 1981) e, como consequência, contribuem para a formação de um ambiente mais favorável à agregação do solo, mas nesse estudo, a gramínea utilizada (milheto) não alterou a estabilidade dos agregados do solo quando comparada com as leguminosas crotalária e feijão-de-porco.

Tabela 4. Diâmetro médio geométrico, diâmetro médio ponderado e distribuição de classes de agregados de um Argissolo Vermelho-Amarelo, antes e após o cultivo de plantas de cobertura

\begin{tabular}{|c|c|c|c|c|c|}
\hline \multirow{3}{*}{ Plantas de cobertura } & \multirow{2}{*}{ DMG } & \multirow{2}{*}{ DMP } & \multicolumn{3}{|c|}{ Distribuição de classes de agregados } \\
\hline & & & $>2 \mathrm{~mm}$ & 2-1 mm & $<1 \mathrm{~mm}$ \\
\hline & \multicolumn{2}{|c|}{$\mathbf{m m}$} & \multicolumn{3}{|c|}{$\%$ de agregados } \\
\hline Testemunha & $3,56 \mathrm{~b}$ & $4,41 a$ & 86,49 & 3,11 & 10,40 \\
\hline $\mathrm{C}_{0,25}$ & $4,19 a$ & $4,63 \mathrm{a}$ & 91,81 & 2,36 & 5,83 \\
\hline $\mathrm{C}_{0,50}$ & $3,83 b$ & $4,49 \mathrm{a}$ & 88,85 & 2,60 & 8,55 \\
\hline $\mathrm{F}_{0,25}$ & $4,12 \mathrm{a}$ & $4,60 \mathrm{a}$ & 91,46 & 2,12 & 6,42 \\
\hline $\mathrm{F}_{0,50}$ & $3,35 \mathrm{c}$ & $4,20 \mathrm{a}$ & 81,58 & 5,55 & 12,87 \\
\hline $\mathrm{M}_{0,25}$ & $4,26 a$ & $4,64 a$ & 92,08 & 2,69 & 5,23 \\
\hline $\mathrm{M}_{0.50}$ & $3,68 \mathrm{~b}$ & $4,41 \mathrm{a}$ & 86,86 & 2,81 & 10,33 \\
\hline
\end{tabular}

Letras iguais nas colunas dentro de cada atributo, não diferem entre si pelo teste de Scott \& Knott, a nível de 5\% de probabilidade. Testemunha = situação anterior ao cultivo das plantas de cobertura; $\mathrm{C}_{0,25}$ e $\mathrm{C}_{0,50}=$ crotalária no espaçamento de 0,25 e $0,50 \mathrm{~m}$, respectivamente; $\mathrm{F}_{0,25}$ e $\mathrm{F}_{0,50}=$ feijão-de-porco no espaçamento de 0,25 e $0,50 \mathrm{~m}$, respectivamente; $\mathrm{M}_{0,25}$ e $\mathrm{M}_{0,50}=$ milheto no espaçamento de 0,25 e $0,50 \mathrm{~m}$, respectivamente. 
Os valores de resistência do solo à penetração, nas parcelas em que foram cultivadas as espécies de plantas de cobertura antes da implantação e 27 dias após o corte das plantas, são apresentados na Figura $2 \mathrm{a}$ e 2b, respectivamente.

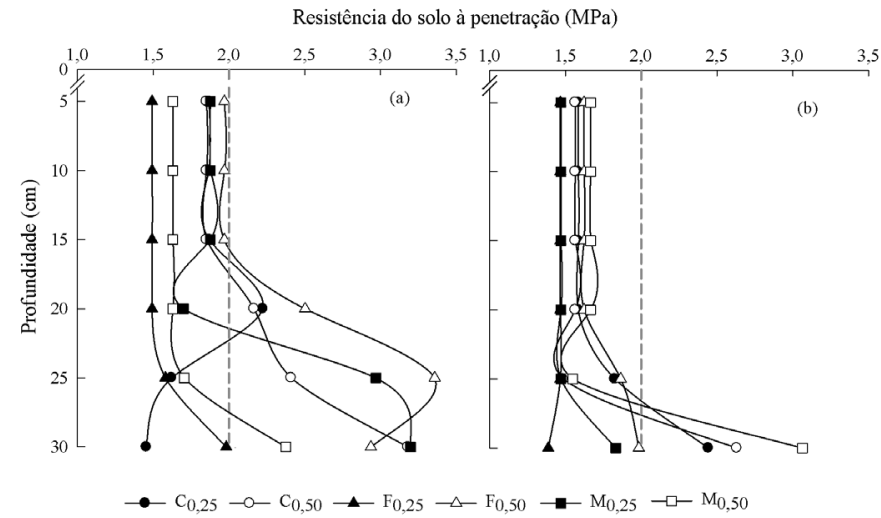

Figura 2. Resistência do solo à penetração, antes (a) e após (b) o cultivo sob plantas de cobertura, em um Argissolo Vermelho-Amarelo distrófico sob crotalária nos espaçamentos de $0,25 \mathrm{~m}\left(\mathrm{C}_{0,25}\right)$ e $0,50 \mathrm{~m}\left(\mathrm{C}_{0.50}\right)$; feijãode-porco no espaçamento de $0,25 \mathrm{~m}\left(\mathrm{~F}_{0,25}\right)$ e $0,50 \mathrm{~m}\left(\mathrm{~F}_{0,50}\right)$, e milheto no espaçamento de $0,25 \mathrm{~m}\left(\mathrm{M}_{0,25}\right)$ e $0,50 \mathrm{~m}\left(\mathrm{M}_{0,50}\right)$

Conforme a Figura 2a, somente na parcela onde foi instalado o tratamento $\mathrm{F}_{0.25}$ não mostrou resistência do solo à penetração maior que $2 \mathrm{MPa}$, valor considerado crítico para o crescimento normal das raízes (Taylor et al., 1966). Os valores mais críticos de resistência à penetração foram encontrados nas camadas subsuperficiais do solo (profundidades maiores que $0,15 \mathrm{~m}$ ), sendo que nas parcelas nas quais foram instaladas $\mathrm{a} \mathrm{C}_{0,50}, \mathrm{M}_{0,25}$ e $\mathrm{F}_{0,50}$ foram encontrados os valores de 3,18; 3,20 e 3,36 MPa, respectivamente. De acordo com o esperado e, por se tratar de um solo com horizonte B textural, maiores valores de resistência à penetração ocorreram nas camadas subsuperficiais em virtude da translocação natural de argila, que ocorre no Argissolo.

De modo geral, a utilização das plantas de cobertura reduziu a resistência do solo à penetração na camada de 0 a 25 $\mathrm{cm}$ (Figura 2b). É provável, que este efeito tenha ocorrido em razão do melhor desenvolvimento do sistema radicular ao longo do ciclo da cultura, com posterior decomposição das raízes. $\mathrm{Na}$ profundidade de $30 \mathrm{~cm}$, a resistência do solo à penetração apontou valores restritivos ao crescimento normal das raízes com valores de 2,44, 2,63 e 3,06 MPa nas parcelas cultivadas com os tratamentos $\mathrm{C}_{0,25}, \mathrm{C}_{0,50}, \mathrm{M}_{0,50}$, respectivamente. A crotalária, por ter um sistema radicular pivotante, possui pequena capacidade de penetrar em camadas com impedimento ao sistema radicular (Burle et al., 2006). Conforme Scaranari (1952), a crotalária e o feijão-de-porco adentram no solo a maior parte das raízes, até uma profundidade de $30 \mathrm{~cm}$; assim, essas plantas possuem a capacidade de reduzir a resistência do solo à penetração até esta profundidade, porém nesse estudo, a influência das raízes foi destacada até a profundidade de $25 \mathrm{~cm}$.

Moreti et al. (2006) verificaram que a crotalária e o milheto cultivados com semeadura direta ou convencional, não modificaram a resistência do solo à penetração na camada superficial do solo, embora nas camadas mais profundas, haja redução da resistência à penetração para as plantas cultivadas, nos dois tipos de manejo do solo.

\section{Conclusões}

O cultivo das espécies de plantas de cobertura altera os teores de potássio e fósforo e não modifica os demais atributos químicos do solo, independente do espaçamento utilizado entre as plantas.

Adensidade do solo, volume total de poros, microporosidade e macroporosidade, não são alterados após o cultivo das plantas de cobertura.

A condutividade hidráulica do solo saturado é bastante influenciada pelas plantas de cobertura; enquanto, a temperatura e a umidade do solo respondem principalmente às alterações ambientais e não ao cultivo instalado.

A crotalária, feijão-de-porco e o milheto possuem a capacidade de reduzir a resistência do solo à penetração para valores não restritivos ao crescimento radicular, até a profundidade de $0,25 \mathrm{~m}$, quando cultivados nos espaçamentos de 0,25 e $0,50 \mathrm{~m}$ entre plantas.

\section{Literatura Citada}

Allmaras, R. R.; Burwull, R. E.; Voorhees, W. B. Aggregate size distribuition in the row zone of tillage experiments. Soil Science Society of America Journal, v.29, n.6, p.645650, 1965. <http://dx.doi.org/10.2136/sssaj1965.03615995 $002900060018 \mathrm{x}>$.

Almeida, V. P.; Alves, M. C; Silva, E. C.; Oliveira, S. A. Rotação de culturas e propriedades físicas e químicas em Latossolo Vermelho de Cerrado sob preparo convencional e semeadura direta em adoção. Revista Brasileira de Ciência do Solo, v.32, n.3, p.1.227-1.237, 2008. <http:// dx.doi.org/10.1590/S0100-06832008000300031>.

Anghinoni, I.; Nicolodi, M. Estratégias de calagem no sistema plantio direto, Lages, SC, 2004. In: Reunião Brasileira de Fertilidade do Solo e Nutrição de Plantas - Fertbio 2004, 26., 2004, Lages, SC. Anais... Lages: Sociedade Brasileira de Ciência do Solo, 2004. CD Rom.

Bavel, C. H. J. M. Mean weight-diameter of soil aggregates as a statistical index of aggregation. Soil Science Society of America Journal, v.14, n.1, p.20-23, 1949. <http://dx.doi. org/10.2136/sssaj1950.036159950014000C0005x>.

Bertoni, J.; Lombardi Neto, F. Conservação do solo. São Paulo: Ícone Editora, 2005. 355p.

Blake, G. R.; Hartge, K. H. Bulk density. In: Klute, A. Methods of soil analysis. Madison: American Society of Agronomy; Soil Science Society of America, 1986. v.1, p.363-375.

Bouma, J. Influence of soil macroporosity on environmental quality. Advances in Agronomy, San Diego, v.46, p.2-36, 1991. <http://dx.doi.org/10.1016/S00652113(08)60577-5>.

Brasil. Ministério da Agricultura e Reforma Agrária. Normais Climatológicas: 1961 - 1990. Brasília: MARA, 1992. $84 \mathrm{p}$.

Burle, M. L.; Carvalho, A. M.; Amabile, R. F.; Pereira, J. Caracterização das espécies de adubo verde. In: Carvalho, A. M.; Amabile, R. F. (Eds.). Cerrado: adubação verde. Planaltina: Embrapa Cerrados, 2006. Cap. 3, p.71-142. 
Calegari, A.; Mondardo, A.; Bulizani, E. A.; Costa, M. B. B.; Miyasaka, S.; Amado, T. J. C. Aspectos gerais da adubação verde. In: Calegari, A.; Mondardo, A.; Bulisani, E. A.; Wildner, L. P.; Costa, M. B. B.; Alcântara, P. B.; Miyasaka, S.; Amado, T. J. C. (Eds.). Adubação verde no sul do brasil. 2. ed. Rio de Janeiro: AS-PTA, 1993. cap.1, p.1-119.

Camargo, O. A.; Alleoni, L. R. F. Compactação do solo e o desenvolvimento das plantas. Piracicaba: ESALQ, 1997. $132 \mathrm{p}$.

Cardoso, D. P. Desempenho de plantas de cobertura no controle da erosão hídrica no Sul de Minas Gerais. Lavras: Universidade Federal de Lavras, 2009. 100p. Tese Doutorado.

Carpenedo, V.; Mielniczuk, J. Estado de agregação e qualidade dos agregados de latossolos roxos, submetidos a diferentes sistemas de manejo. Revista Brasileira de Ciência do Solo, v14, n.1, p.99-105, 1990.

D'Agostini, L. R. Recuperação física do solo por sistemas de cultivo. Porto Alegre: Universidade do Rio Grande do Sul, 1981. 76p. Dissertação Mestrado.

Danielson, R. E.; Sutherland, P. L. Porosity. In: Klute, A. (Ed.). Methods of soil analysis. 2.ed. Madison: American Society of Agronomy, 1986. p. 443-61.

Delhaize, E.; Ryan, P. R. Aluminum toxicity and tolerance in plants. Plant Physiology. v.107, n.2, p.315-321, 1995. $<$ http://dx.doi.org/10.1104/pp.107.2.315>.

Empresa Brasileira de Pesquisa Agropecuária. Centro Nacional de Pesquisa de Solo. Sistema brasileiro de classificação de solos. Rio de Janeiro: Embrapa Solos, 2006. 306p.

Empresa Brasileira de Pesquisa Agropecuária. Serviço Nacional de Levantamento e Conservação do Solo. Manual de métodos de análises do solo. Rio de Janeiro: Embrapa Solos, 1997. 212p.

Fabian, A. J. Plantas de cobertura: efeito nos atributos do solo e na produtividade de milho e soja em rotação. Jaboticabal: Universidade Estadual Paulista "Julio de Mesquita Filho", 2009. 83p. Tese Doutorado.

Faria, C. M. B.; Soares, J. M; Leão, P. C. S. Adubação verde com leguminosas em videira no submédio São Francisco. Revista Brasileira de Ciência do Solo, v.28, n.4, p.641-648, 2004. <http://dx.doi.org/10.1590/S010006832004000400006>.

Ferreira, D. F. Análises estatísticas por meio do Sisvar para Windows versão 4.0. In: Reunião Anual da Região Brasileira da Sociedade internacional de Biometria, 45., 2000, São Carlos. Anais... São Carlos: UFSCar, 2000. p. $255-258$.

Grohmann, F. Distribuição do tamanho de poros em três tipos de solo do Estado de São Paulo. Bragantia, v.19, n.único, p.319-328, 1960. <http://dx.doi.org/10.1590/S0006$87051960000100021>$.

Hickmann, C.; Costa, L. M.; Schaefer, C. E. G. R.; Fernandes, R. B. A. Morfologia e estabilidade de agregados superficiais de um Argissolo Vermelho Amarelo sob diferentes manejos de longa duração e mata atlântica secundária. Revista Brasileira de Ciência do Solo, v.35, n.6, p.2191-2198, 2011. <http://dx.doi.org/10.1590/ S0100-06832011000600034>.
Lessa, L. G. F.; Lima, S. L; Zimback, C. R. L. Análise multitemporal das perdas de solo por voçorocas, da sub-bacia Ribeirão das Bicas - Botucatu/SP, através de geoprocessamento e sensoriamento remoto. Energia na Agricultura, v.22, n.1, p.61-74, 2007. $<$ http://200.145.140.50/html/CD_REVISTA_ENERGIA_ vol9/vo122n12007/artigos/Luis\%20Gustavo\% $2 \overline{0}$ Frediani\%20Lessa.pdf $>$.

Menezes, L. A. S.; Leandro, W. M. Avaliação de espécies de coberturas do solo com potencial de uso em sistema de plantio direto. Pesquisa Agropecuária Tropical, v.34, n.3, p.173-180, 2004. <http://www.revistas.ufg.br/index.php/ pat/article/viewArticle/2311>.

Mielniczuk, J. Matéria orgânica e sustentabilidade de sistemas agrícolas. In: Santo, G. A.; Camargo, F. A. O. (Eds.). Fundamentos da matéria orgânica do solo ecossistemas tropicais e subtropicais. Porto Alegre: Genesis, 1999. p.1-8.

Moreira, F. M. S.; Siqueira, J. O. Microbiologia e bioquímica do solo. Lavras: Editora UFLA, 2002. 626p.

Moreti, D.; Alves, M. C.; Perozini, A. C.; Paz Gonzalez, A.; Silva, E. C. Condutividade hidráulica e resistência à penetração do solo influenciada por diferentes sistemas de manejo. Cadernos do Laboratório Xeolóxico de Laxe, v.31, n.1, p.29-42, 2006. <http://ruc.udc.es/ dspace/bitstream/2183/6317/1/CA-31-3.pdf $>$. 11 Fev. 2012.

Moreti, D.; Alves, M. C.; Valério Filho, W. V.; Carvalho, M. P. Atributos químicos de um latossolo vermelho sob diferentes sistemas de preparo, adubações e plantas de cobertura. Revista Brasileira de Ciência do Solo, v.31, n.1, p.167-175, 2007. <http://dx.doi.org/10.1590/S010006832007000100017>.

Nascimento, J. T.; Silva, I. F. S.; Santiago, R. D.; Silva Neto, L. F. Efeito de leguminosas nos atributos físicos e carbono orgânico de um Luvissolo. Revista Brasileira de Ciência do Solo, v.29, n.5, p.825-831, 2005. <http://dx.doi. org/10.1590/S0100-06832005000500018>.

Nuernberg, N. J.; Stammel, J. G.; Camanurea, M. S. V. Efeito de sucessão de culturas e tipos de adubação em características físicas de um solo da encosta basáltica SulRio-Grandense. Revista Brasileira de Ciência do Solo, v.10, n.3, p.185-190, 1986. <http://people.ufpr.br/ jair/ A1716/Artigos/7.\%20EfeitodeSucessoesdeculturas.pdf $>$. 12 Fev. 2013.

Oliveira, V. S.; Rolim, M. M.; Vasconcelos, R. F. B.; Pedrosa, E. M. R. Distribuição de agregados e carbono orgânico em um Argissolo Amarelo distrocoeso em diferentes manejos. Revista Brasileira de Engenharia Agrícola e Ambiental, v.14, n.9, p.907-913, 2010. <http://dx.doi.org/10.1590/ S1415-43662010000900001>.

Portugal, A. F.; Juncksh, I.; Schaefer, C. E. R. G.; Neves, J. C. L. Estabilidade de agregados em argissolo sob diferentes usos, comparado com mata. Revista Ceres, v.57, n.4, p.545-553, 2010. <http://dx.doi.org/10.1590/S0034$737 \times 2010000400018>$. 
Reinert, D. J.; Albuquerque, J. A.; Reicher, J. M.; Aita, C.; Andrada, M. M. C. Limites críticos de densidade do solo para o crescimento de raízes de plantas de cobertura em Argissolo Vermelho. Revista Brasileira de Ciência do Solo, v.32, n.5, p.1805-1816, 2008. <http://dx.doi.org/10.1590/ S0100-06832008000500002>.

Ribeiro, A. C.; Guimarães, P. T. G.; Alvarez, V. V. H. Recomendação para o uso de corretivos e fertilizantes em Minas Gerais. Viçosa-MG: Comissão de Fertilidade do Solo do Estado de Minas Gerais, 1999. 359p.

Scaranari, H. J.; Inforzato, R. Sistema radicular das principais leguminosas empregadas como adubo verde em cafezal. Bragantia, v.12, n.7-9, p.291-296, 1952. <http://dx.doi. org/10.1590/S0006-87051952000300008>.

Schlindwein, J. A.; Nolla, A.; Anghinoni, I.; Meurer, E. J. Redução da toxidez de alumínio em raízes de soja por culturas antecessoras no sistema plantio direto. Revista Brasileira de Agrociência, v.9, n.1, p.85-88, 2003. <http:// www.ufpel.tche.br/faem/agrociencia/v9n1/artigo16.pdf >. 12 Fev. 2013.

Scott, S. J.; Knott, M. A. A cluster analysis method for grouping means in the analysis of variance. Biometrics, v.30, n.3, p.507-512, 1974. <http://dx.doi.org/10.2307/2529204>.

Silva, R. H.; Rosolem, C. A. Crescimento radicular de soja em razão da sucessão de cultivos e da compactação do solo. Pesquisa Agropecuária Brasileira, v.37, n.6, p.855-860, 2002. <http://dx.doi.org/10.1590/S0100204X2002000600015>.

Silveira, P. M. da; Cunha, P. C. R. da; Stone, L. F.; Santos, G. G. dos. Atributos químicos de solo cultivado com diferentes culturas de cobertura. Pesquisa Agropecuária Tropical, v. 40, n. 3, p. 283-290, 2010. <http://dx.doi.org/10.5216/pat. v40i3.5841>.
Stolf, R. Teoria e teste experimental de fórmulas de transformação dos dados de penetrômetro de impacto em resistência do solo. Revista Brasileira de Ciência do Solo, Viçosa-MG, v.15, n.3, p.229-235, 1991. <http://www.cca.ufscar.br/ drnpa/hprubismar_ARTIGOS/63._Teoria_e_teste_de transformacao_dos_dados_de_penetrometro_de_impacto em_resistencia_do_solo_(Stolf,R.).pdf $>$. 12 Fev. 2013.

Stone, L. F.; Silveira, P. M. Efeitos do sistema de preparo e da rotação de culturas na porosidade e densidade do solo. Revista Brasileira de Ciência do Solo, v.25, n.2, p.395-401, 2001. <http://sbcs.solos.ufv.br/solos/revistas/v25n2a15. pdf>. 12 Fev. 2013.

Taylor, H. M., Roberson, G. M.; Parker Jr., J. J. Soil strengthroot penetration relations to medium to coarsetextured soil materials. Soil Science, v.102, n.1, p.18-22, 1966. <http:// dx.doi.org/10.1097/00010694-196607000-00002>.

Tisdall, J. M.; Oades, J. M. Organic matter and waterstable aggregates in soils. European Journal of Soil Science, v.33, n.2, p.141-163, 1982. <http://dx.doi. org/10.1111/j.1365-2389.1982.tb01755.x>.

Torres, J. L. R.; Pereira, M. G. Dinâmica do potássio nos resíduos vegetais de plantas de cobertura no Cerrado. Revista Brasileira de Ciência do Solo, v.32, n.4, p.1609-1618, 2008. <http://dx.doi.org/S0100-06832008000400025>.

Torres, J. L. R.; Pereira, M. G.; Fabian, A. J. Produção de fitomassa por plantas de cobertura e mineralização de seus resíduos em plantio direto. Pesquisa Agropecuária Brasileira, v.43, n.3, p.421-428, 2008. <http://dx.doi. org/10.1590/S0100-204X2008000300018>.

Wendling, B.; Jucksch, I.; Mendonça, E. S.; Neves, J. C. L. Carbono orgânico e estabilidade de agregados de um Latossolo Vermelho sob diferentes manejos. Pesquisa Agropecuária Brasileira, v.40, n.5, p.487-494, 2005. $<$ http://dx.doi.org/10.1590/S0100-204X2005000500010>. 